\title{
Intravascular papillary endothelial hyperplasia (Masson's hemangioma) of the face
}

\author{
Jin Woo Han ${ }^{1}$, \\ Jong Hun Lee ${ }^{1}$, \\ Eun Kyung Kim ${ }^{2}$ \\ Departments of ${ }^{1}$ Plastic and \\ Reconstructive Surgery and ${ }^{2}$ Pathology, \\ Nowon Eulji Medical Center, Eulji \\ University School of Medicine, Seoul, \\ Korea
}

\begin{abstract}
Intravascular papillary endothelial hyperplasia or Masson's hemangioma is a rare vascular tumor. The reactive proliferation of endothelial cells in this disease mimics other benign or malignant vascular proliferation such as angiosarcoma or Kaposi's sarcoma. It is important to make an accurate distinction to avoid confusion with these malignant tumors. This would facilitate a proper diagnosis, which is essential so that the patient is not subjected to unnecessarily aggressive or inappropriate treatment.
\end{abstract}

Keywords: Benign tumor / Intravascular papillary endothelial hyperplasia / Masson's hemangioma

\section{INTRODUCTION}

Intravascular papillary endothelial hyperplasia (IPEH) or Masson's hemangioma is a rare disease that accounts for approximately $2 \%$ of skin and soft tissue vascular tumors [1]. Only one case of this disease has been reported in the plastic surgery literature, and none from Korea [2]. Clinical features of IPEH include a striking similarity to benign tumors such as mucocele, pyogenic granuloma and hemangioma as well as malignant tumors such as angiosarcoma and Kaposi's sarcoma [3]. Clinically, IPEH manifests as a firm or tender nodule or a slightly elevated mass that appears red or blue on the skin, with sharp demarcation and slow growth [4]. We report a rare case of IPEH of the nasolabial fold to emphasize the importance of accurately distinguishing it for other malignant tumor such as angiosarcoma.

\section{CASE REPORT}

A 51-year-old male patient presented with a 1-month history of

Correspondence: Jong Hun Lee

Department of Plastic and Reconstructive Surgery, Nowon Eulji Medical Center,

Eulji University School of Medicine, 68 Hangeulbiseong-ro, Nowon-gu, Seoul

01830, Korea

E-mail: joaljh@eulji.ac.kr

Received September 27, 2018 / Revised October 26, 2018 / Accepted November 6, 2018 a telangiectatic palpable mass on his left nasolabial fold. Physical examination revealed a firm, painless, and noninflammatory swelling below the left nasal ala, without any remarkable findings on ear, throat, and head and neck examinations (Fig. 1). Excision of the mass was performed under local anesthesia. It was well-demarcated and had small feeding vessels and the texture was moderately firm (Fig. 2).

Histopathological examination revealed a nodule with a thickwalled blood vessel filled with papillary structures and blood (Fig. 3). The papillary structures were lined by a single layer of flattened endothelial cells and supported by fibrous stroma (Fig. 4). The endothelial cells were positive for CD34 (Fig. 5).

\section{DISCUSSION}

IPEH was first described by Masson in 1923 as "hemangioendotheliome vegetant intravasculaire" and was also referred to by various names such as "papillary fibroendothelioma" and "intravascular endothelioma," "papillary proliferation of the endothelium," "papillary endothelioma," "hemangioendotheliome vegetant intravasculaire," "lendovasculite proliferante trombopoietique," "intravenous atypical vascular proliferation," "intravascular angiomatosis," "intravascular papillary endothelial hyperplasia," "Masson's vegetant intravascular hemangioendothe- 


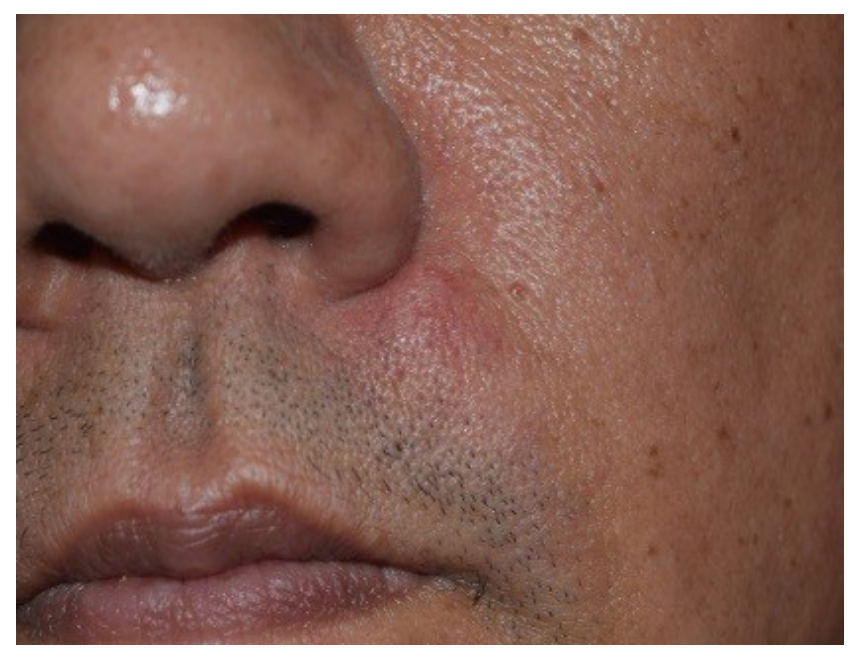

Fig. 1. Preoperative image of the lesion on the left nasolabial fold. It presented as a telangiectatic, soft and painless swelling.

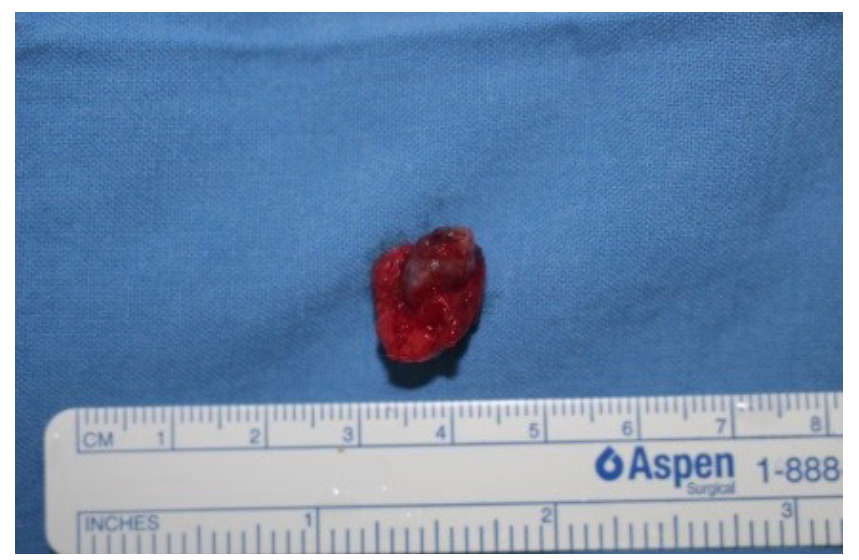

Fig. 2. Gross finding of a resected tissue. It was well-demarcated and moderately firm mass.

lioma," "Masson's pseudoangiosarcoma," "intravascular endothelial hyperplasia," "Masson's lesion," and "papillary endothelial hyperplasia." In 1976, Clearkin and Enzinger introduced the term intravascular papillary endothelial hyperplasia, which is now used in most literature [1].

This benign lesion consists of papillary formation associated with a thrombus and reactive proliferation of endothelial cells mimicking other types of benign and malignant vascular proliferation. IPEH is mostly an intravascular lesion, but extravascular hematoma organization features may also be present [5]. IPEH is clinically important because it can be confused with other malignant neoplasms such as vascular malformation, angiosarcoma, and Kaposi's sarcoma. Demonstration of vascular origin and proliferative index by immunohistochemistry can contribute to an accurate differential diagnosis of IPEH. It is a non-neoplastic vascular proliferative process in normal blood vessels or a vascular malformation and is characterized histologically by the

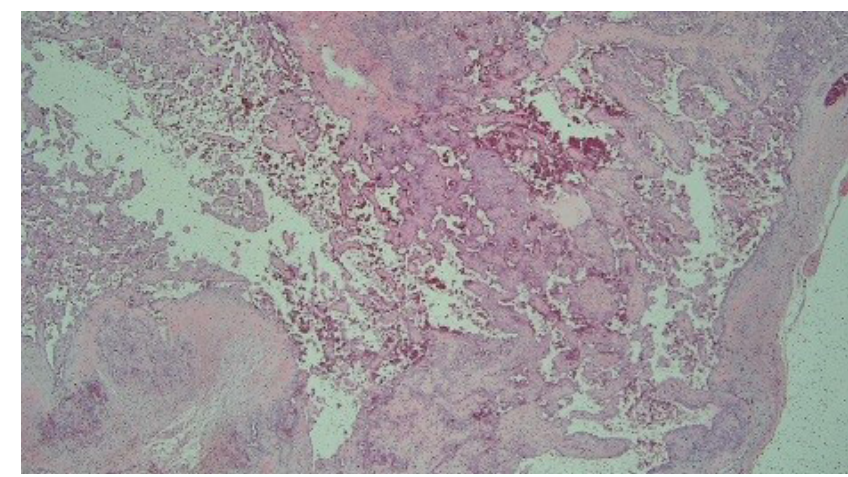

Fig. 3. The nodule showed a thick-walled blood vessel filled with papillary structures and blood. Dilated vessel with multiple papillary structures projecting into the lumen was seen $(\mathrm{H} \& \mathrm{E}, \times 100)$.

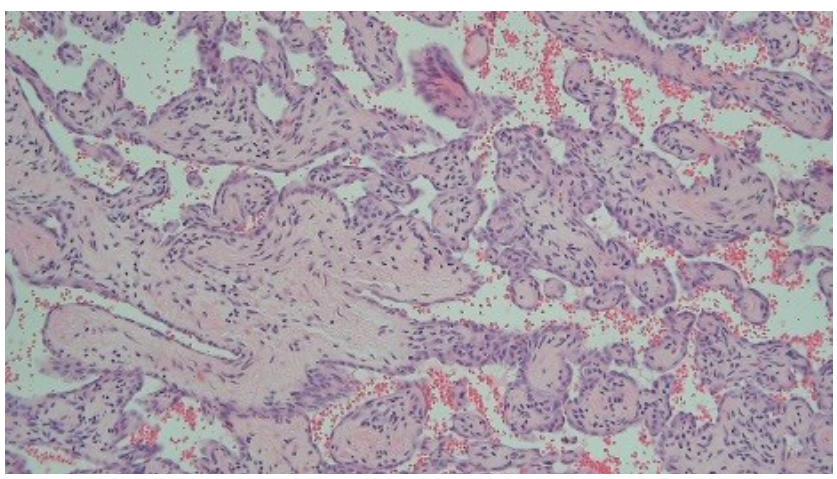

Fig. 4. The papillary structures were lined by a single layer of flattened endothelial cells and supported with fibrous stroma. Endothelial proliferation with papillary projection and capillaries with blood cells inside were also seen $(\mathrm{H} \& \mathrm{E}, \times 200)$.

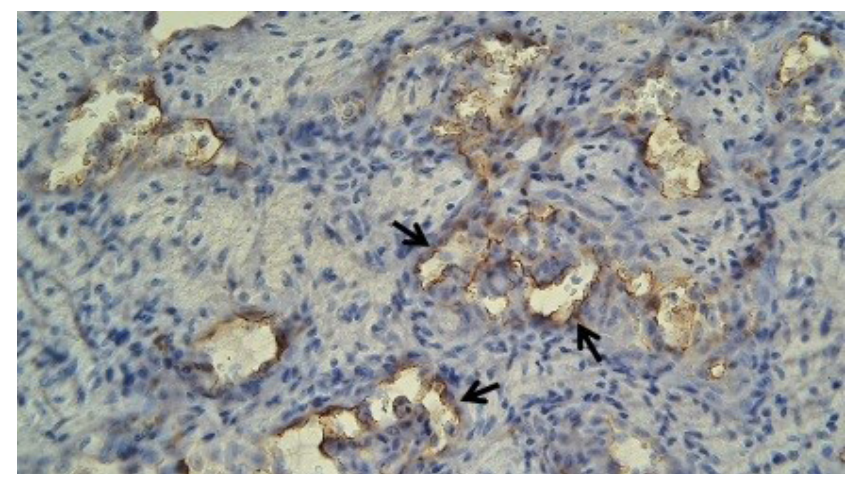

Fig. 5. The endothelial cells were positive for CD34 (arrows). Immunohistochemically, brown cytoplasmic staining of the endothelial cells of CD34 is considered a positive reaction $(\times 200)$.

proliferating endothelium-lined papillary fronds [6].

Basic histological features of IPEH include a formation of papillary structures with hyperplastic endothelial cells lined up in the lumen of the blood vessels. CD31 and CD34 are expressed in the lesions at maturity level, and they are the most effective markers for identifying the vascular root. They have a 
strongly staining immature endothelium covering multiple small papillary structures (lining endothelial cells) and mature well-formed vessels [3]. A critical distinction between angiosarcoma and IPEH is that angiosarcoma is typically not present in the lumen of vessels. Moreover, unlike angiosarcoma, the endothelial cells of IPEH lack necrosis, marked pleomorphism, significant mitotic activity, and solid sheet formation [7].

The prognosis of IPEH is good because it does not progress to a malignant tumor or recur after appropriate resection. Benign IPEH lesions are completely cured by local excision. However, because angiosarcoma is a malignant tumor capable of metastasis, localized surgical removal alone may not completely eliminate it. Failure to identify these differences can lead to misdiagnosis followed by overly aggressive treatment. Therefore, a clear understanding of the differences is needed, and this case is reported to emphasize its importance.

\section{NOTES}

\section{Conflict of interest}

No potential conflict of interest relevant to this article was reported.

\section{Ethical approval}

The study was performed in accordance with the principles of the Declaration of Helsinki. Written informed consent was obtained.

\section{Patient consent}

The patient provided written informed consent for the publication and the use of his images.

\section{ORCID}

Jin Woo Han http://orcid.org/0000-0002-8871-2699

Jong Hun Lee http://orcid.org/0000-0001-6417-6986

Eun Kyung Kim http://orcid.org/0000-0001-6701-6988

\section{REFERENCES}

1. Guledgud MV, Patil K, Saikrishna D, Madhavan A, Yelamali T. Intravascular papillary endothelial hyperplasia: diagnostic sequence and literature review of an orofacial lesion. Case Rep Dent 2014;2014:934593.

2. Boukovalas S, Dillard R, Qiu S, Cole EL. Intravascular papillary endothelial hyperplasia (Masson's tumor): diagnosis the plastic surgeon should be aware of. Plast Reconstr Surg Glob Open 2017;5:e1122.

3. Akdur NC, Donmez M, Gozel S, Ustun H, Hucumenoglu S. Intravascular papillary endothelial hyperplasia: histomorphological and immunohistochemical features. Diagn Pathol 2013; 8:167.

4. Makos CP, Nikolaidou AJ. Intravascular papillary endothelial hyperplasia (Masson's tumor) of the oral mucosa: presentation of two cases and review. Oral Oncol Extra 2004;40:59-62.

5. Pins MR, Rosenthal DI, Springfield DS, Rosenberg AE. Florid extravascular papillary endothelial hyperplasia (Masson's pseudoangiosarcoma) presenting as a soft-tissue sarcoma. Arch Pathol Lab Med 1993;117:259-63.

6. Soares AB, Altemani A, Furuse C, Demasi AP, Gati C, Nunes N, et al. Intravascular papillary endothelial hyperplasia: report of 2 cases and immunohistochemical study. Oral Surg Oral Med Oral Pathol Oral Radiol Endod 2008;106:708-11.

7. Kim DS, Ryu DJ, Oh SH, Lee MG. Intravascular papillary endothelial hyperplasia simulating malignant melanoma. Acta Derm Venereol 2010;90:220-1. 